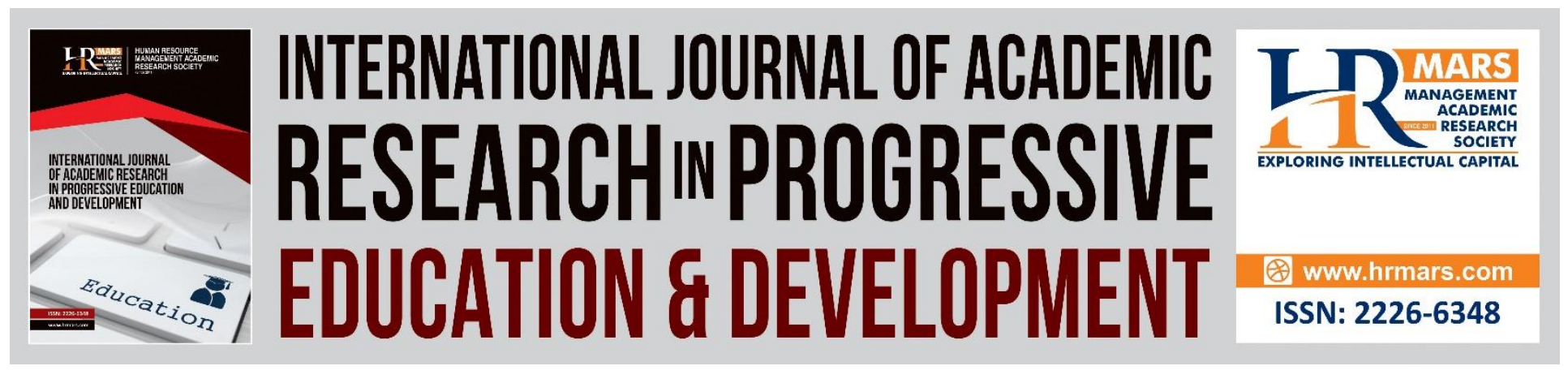

\title{
Application of Token Economy to Decrease Pacifier use on a Child with Cerebral Palsy
}

Khairul Farhah Khairuddin, Mohd Hanafi Mohd Yasin, Nur Syuhada Hosni

To Link this Article: http://dx.doi.org/10.6007/IJARPED/v8-i4/6774

DOI:10.6007/IJARPED/v8-i4/6774

Received: 15 November 2019, Revised: 30 November 2019, Accepted: 11 December 2019

Published Online: 30 December 2019

In-Text Citation: (Khairuddin et al., 2019)

To Cite this Article: Khairuddin, K. F., Yasin, M. H. M., \& Hosni, N. S. (2019). Application of Token Economy to Decrease Pacifier use on a Child with Cerebral Palsy. International Journal of Academic Research in Progressive Education and Development, 8(4), 836-845.

Copyright: (C) 2019 The Author(s)

Published by Human Resource Management Academic Research Society (www.hrmars.com)

This article is published under the Creative Commons Attribution (CC BY 4.0) license. Anyone may reproduce, distribute, translate and create derivative works of this article (for both commercial and non-commercial purposes), subject to full attribution to the original publication and authors. The full terms of this license may be seen

at: $\underline{\text { http://creativecommons.org/licences/by/4.0/legalcode }}$

\section{Vol. 8(4) 2019, Pg. 836 - 845}

http://hrmars.com/index.php/pages/detail/IJARPED

JOURNAL HOMEPAGE

Full Terms \& Conditions of access and use can be found at http://hrmars.com/index.php/pages/detail/publication-ethics 


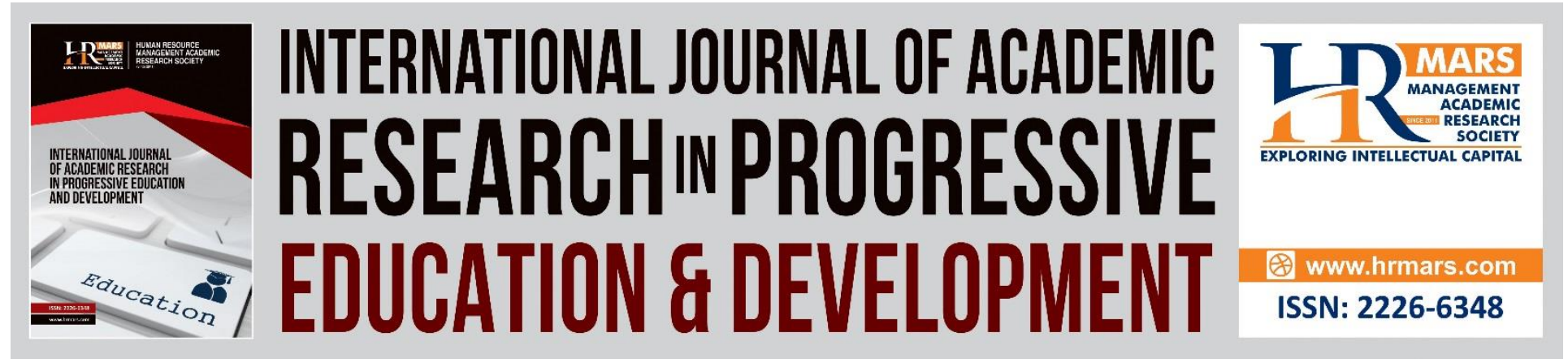

\title{
Application of Token Economy to Decrease Pacifier use on a Child with Cerebral Palsy
}

\author{
Khairul Farhah Khairuddin, Mohd Hanafi Mohd Yasin
}

Faculty of Education, Universiti Kebangsaan Malaysia, 43600 Bangi, Malaysia

\author{
Nur Syuhada Hosni \\ Malaysian Health Ministry, Kompleks E, Pusat Pentadbiran Kerajaan Persekutuan 62590 \\ Putrajaya, Malaysia \\ Email: mhmy6365@ukm.edu.my
}

\begin{abstract}
The purpose of this study is to assess the effectiveness of a token economy program to bring about total avoidance of pacifier use by a five-year-old child with Cerebral Palsy. A token economy is one of the most commonly used techniques to manage the behavior of children with special needs. This study uses a single-case study with an A-B-A design, where A represents the baseline phase, $B$ represents the intervention phase, and $A$ is the second baseline phase of the withdrawal of intervention without the use of token economy. The data was collected through home observation for four weeks involving three phases in which the first week was for baseline phase, two weeks for intervention and the final week for second baseline phase after the withdrawal of intervention. The results showed that the mean frequency of pacifier usage for the baseline (A) was 90 minutes, while the mean intervention frequency (B) was 35 minutes, and the mean frequency after intervention withdrawal $(A)$ was only 15 minutes. The findings showed that there was a reduction in the frequency of the usage of pacifier after the intervention was conducted and the reduction was sustained even after intervention was withdrawn. This suggests that the token economy technique applied in this study is deemed to be suitable and can be used even for children with limited mobility such as those afflicted by cerebral palsy.
\end{abstract}

Keywords: Behavior Management, Cerebral Palsy, Pacifier Usage, Token Economy

\section{Introduction}

Meeting the needs of children with disabilities has been challenging in the $21^{\text {st }}$ century, with increasing concern to improve development of the individual child holistically (Amran, Majid, \& Ali, 2019). Some of the concerns include the management of behavior that interfere with their social development. Token economy is one of the most frequently used techniques in supporting positive behavior among children with disabilities (Sugai et al., 2000). Specifically, it has been an 
effective intervention to increase targeted behaviors, improve social skills, and thus indirectly reduce behavioral problems (Reitman, Murphy, Hupp, \& O'Callaghan, 2004). It has been considered as the fastest and most effective strategy to reinforce children's positive behavior compared to other behavior management approaches such as cognitive behavioral therapy technique (Matson \& Boisjoli, 2009). Tokens can be distributed to individuals or a large number of children even during busy daily routines because the provision of reinforcers can be delayed when sufficient amount has been obtained. Another advantage of this approach is that it could be applied at school setting as well as at home - which is the focus of this paper.

The first part of this paper presents debates in nonnutritive-sucking and highlights the importance of reducing such oral behavior among young children. Much of these studies are based on medical, nursing and psychological literature, with little attention on the strategies to intervene when necessary (Adair, 2003). The second part discusses debates in the use of token economy as a strategy to increase desired behavior. The methodology section presents the overall design of this study which aimed to quantify the total time of pacifier use by a child identified as Adam. The final part of this paper discusses issues pertaining to the use of token economy to manage the behavior exhibited by a child with cerebral palsy.

\section{Literature Review}

There are growing international debates on the use of pacifiers due to contradictory findings of its benefits and drawbacks. Pacifiers served as a soother for premature babies and have been found to lower the risk of Sudden Infant Death Syndrome (Marter \& Agruss, 2007). However, persistent habits of pacifier use after the age of three have been found to affect children's health, safety and wellbeing. Some of the risks include increased frequency of otitis media, malocclusion (misalignment between the teeth) and other oral abnormalities (Hanafin \& Griffiths, 2002; Jenik $\&$ Vain, 2009). Research also shows that prolonged pacifier use has positive association with fuss behavior among children (Kramer et al., 2001) or worse, smoking habits among adolescents (Ferreira et al., 2015).

Analysis of the challenges faced by teachers of children with disabilities reported that children's communication is one of the most mentioned issue (Alias \& Salleh, 2017). Teachers have also reported lack of social-emotional competencies (Mohamed et al., 2019). This is not surprising since it is also reported that most children with disabilities have some kind of oral sucking habits (Carneiro, Monteiro, Pordeus, \& Borges-Oliveira, 2017). The use of pacifiers among children with disabilities was found to be common due to a variety of reasons including the soothing properties of pacifiers and because there is a lack of parents' control over the habit. Bruxism (teeth grinding), throat infection and mouth breathing are some of the long-term effects of oral sucking habits. This justifies the need to establish strategies to minimize the deleterious consequences of such behavior because sucking habits do not necessarily cease with age. Without behavior management intervention, children may continue the oral sucking habit until adult-age which may harm their quality of life. 
Vol. 8, No. 4, 2019, E-ISSN: 2226-6348 @ 2019 HRMARS

Children with cerebral palsy have motor dysfunction that may be associated with sensory or cognitive disabilities resulting from non-progressive brain damage during their development. The impairment can happen before, during or after birth which affects motor function, intellectual ability, swallowing, vision and hearing. Considering the limited maturation of the central nervous system, some children have difficulties in finding comfort in breastfeeding, and thus tend to develop other sucking habits related to primitive oral reflexes including the use of pacifier.

The frequency of non-nutritive sucking among children with cerebral palsy is high (Ortega, Guimarães, Ciamponi, \& Marie, 2007; Mugweni, Chinyoka, \& Chinyoka, 2018; Sljabat, 2018) More than $70 \%$ of children with cerebral palsy in researches have been found to possess habits, including pacifier use. Development of a systematic and organized plan is necessary in order to reduce prolonged habit and its consequences. This paper aims to explore the effectiveness of token economy as a strategy to increase total avoidance of pacifier use.

\section{Methodology}

There are several principles and procedures to follow prior to the implementation of a reinforcement program. Miltenberger (2015) suggests that firstly researchers need to be clear of the targeted behavior that needs intervention. Then, researchers identify the type of token to give to children when they present the desired behavior. Tokens must be tangible where children can see, touch and count with appropriate size, so they can store or collect. Researchers also need to identify the actual reinforcers for the tokens that children have collected. Token economy programs should also have a set timeframe to receive the token and reinforcers with the agreed amount of tokens for reasonable reinforcers. It is also possible to take the token back as part of the program rules for inappropriate behavior (Zirpoli, 2008).

This study follows a single-subject design approach to investigate the effectiveness of the behavior change program on pacifier use. One main advantage of single-subject design approach is so that researchers can demonstrate the effectiveness of an intervention used for a particular child. It is ideal for researchers to understand the relationship between an intervention program and the behavior changes displayed by a single child (Odom \& Strain, 2002). Analysis of singlesubject research design in the literature revealed that the approach is underrated (Hammond \& Gast, 2010). This study aims to add knowledge in order to fill this gap.

Data is collected at baseline (referred to condition A) and intervention (referred to B) phase. There are a number of single-subject designs, but for the purpose of the present study, an A-B-A design is implemented, whereby $A$ refers to the first data collected prior to the implementation of a behavior intervention program. Data in phase $B$ refers to the data after intervention was conducted and the second $A$ refers to data after intervention is withdrawn. The whole design took four weeks to complete. The purpose of A-B-A design is to demonstrate a clear relationship between children's behavior change and the intervention provided. An increase in a child's behavior after intervention is introduced demonstrates the effectiveness of the intervention. Meanwhile, a decrease in a child's performance after the elimination of 
intervention suggests a need to return to the intervention program (Jones \& Kazdin, 1975). Data is presented in graphs to illustrate the changes.

The whole study was conducted from November 2018 to March 2019. The child who participated is known as Jeff. He was five years old at the time of the study. Jeff was identified to have cerebral palsy at the age of three months after he had severe fever and epilepsy. His parents thought that pacifier use could help to reduce Jeff's drooling habit. Due to prolonged usage of the pacifier, Jeff had difficulties in producing speech which also related to his dental problems. According to the parents, Jeff was referred to a rehabilitation specialist to manage his drooling habit. Medical management of his drooling and pacifier use had not yielded a positive indicator that they were decreasing, so researchers planned a token economy program to support Jeff's needs.

After obtaining permission from the parents, researchers sent a draft of the plan about the types of token, procedures, and assessment strategies to the parents for review. After both researchers and parents had agreed on the plan, an observation was conducted involving three phases. Behavior observation and measures were conducted by parents at home for three hours, from $6 \mathrm{pm}$ to $9 \mathrm{pm}$ every day for four consecutive weeks. This particular time was selected since parents would be home after work and be able to focus on observing the child. The recording chart was checked by researchers at the end of every week. As mentioned above, the first phase is the baseline conducted in a week. The intervention was conducted for two weeks, and another observation was conducted for a week in the final phase after intervention was withdrawn.

The behavioral intervention program in this study was through a token economy program. During the intervention phase, there were rules established with the child on how to gain a token and how much is needed for an exchange with agreed reinforcement. Jeff's parents identified balloon, chocolate and a ride on the train in the mall for the actual reinforcements in exchange for the tokens. Visual aid for the options is in Image 1 below. It is crucial for researchers to identify the favorite items and activities suitable for the child to be attracted to participate (Doll, McLaughlin, \& Barretto, 2013).

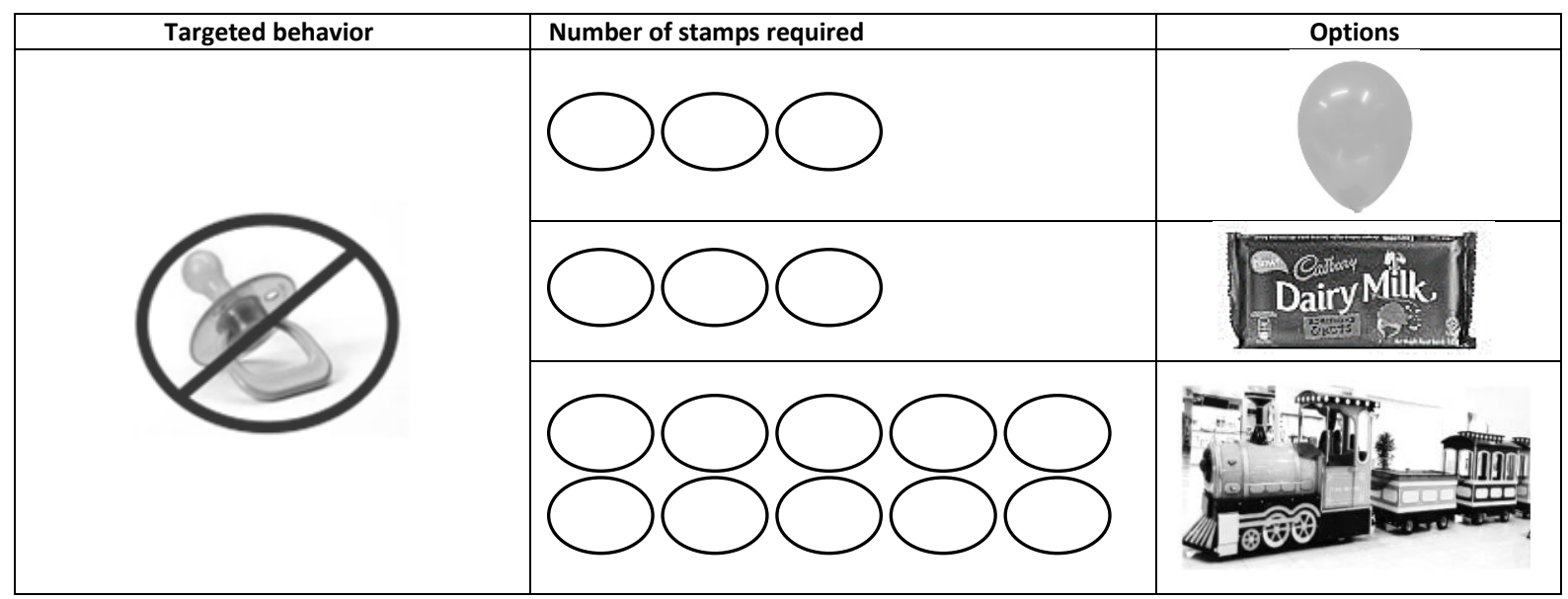

Image 1: Example of the token economy reinforcement sheet 
Tokens used in this study were stamps whereby Jeff could practice his motor skills. The movement of stamping is easier compared to the use of sticker. Three stamps were required for an exchange of a balloon or chocolate, and ten stamps were required to get a train ride. Jeff gets a stamp whenever he removes the pacifier. Description of the activity is presented in Table 1 below.

\begin{tabular}{lll}
\hline Activity & Number of tokens & Reinforcement options \\
\hline $\begin{array}{l}\text { Removal of the pacifier when } \\
\text { reminded by parents }\end{array}$ & $\begin{array}{l}1 \text { stamp for the } \\
\text { compliance }\end{array}$ & $\begin{array}{l}\text { Three stamps for an exchange } \\
\text { of a piece of chocolate or a } \\
\text { balloon }\end{array}$ \\
$\begin{array}{l}\text { Playing and watching } \\
\text { television without using the } \\
\text { pacifier }\end{array}$ & $\begin{array}{l}1 \text { stamp for the whole } \\
\text { session }\end{array}$ & $\begin{array}{l}\text { Ten stamps for an exchange of } \\
\text { train ride in a mall near Jeff's } \\
\text { home }\end{array}$ \\
\hline
\end{tabular}

Table 1: Description of the token economy program

Structured observation method was implemented from $6 \mathrm{pm}$ to $9 \mathrm{pm}$. Parents marked the time in minutes when Jeff did not use pacifier in the frequency recording forms prepared by researchers. Descriptive analysis was conducted to measure the total time when Jeff did not use pacifier.

\section{Results and Discussion}

The objective of the study is to assess the effectiveness of a token economy program to decrease the total time of pacifier use by a child with cerebral palsy. Table 2 presents the duration of pacifier use (in minutes) in Baseline phase (A), intervention phase (B) and baseline phase (A) after the withdrawing of intervention. It was reported that the duration of pacifier use was high in the baseline phase compared to the intervention and second baseline phase. The longest duration was reported on Day Four of the baseline phase which was inferred to Jeff's playing and sleeping time.

There was a significant decrease in duration after the intervention was introduced. Within two weeks of intervention, the pacifier use time had decreased to 10 minutes from the first day of intervention, which was at 75 minutes. The token economy was shown to be effective to reduce pacifier use of the child in this study. In the second week of intervention, it was found that there is a consistent decrease in pacifier usage time from 20 minutes to 10 minutes a day. The parents reported Jeff only used the pacifier to help him sleep. He did not use pacifier while playing and watching television. The parents also reported that Jeff spoke more without pacifier use. In the fourth week of observation, the duration of pacifier use increased slightly to 25 minutes on the first day of the withdrawal of intervention. This duration decreased slightly to 10 minutes and was only demonstrated before sleep time. 
Vol. 8, No. 4, 2019, E-ISSN: 2226-6348 @ 2019 HRMARS

The average duration of pacifier use within the three phases is shown in Table 3. Mean of the duration decreased significantly from 88.6 minutes to only 37.5 minutes after the token economy program was implemented. The data suggests that the two-week intervention had been helpful because even after the removal of intervention, the total duration of pacifier use decreased to only 15 minutes. Token economy system is a suitable intervention for the child and effective to increase desired behavior. The study, however, did not look into other possible strategies, such as praise, that parents may have used after withdrawing the token reinforcement program that contributes to the decreased pacifier use time.

\begin{tabular}{|c|c|c|c|c|}
\hline Week & Day & $\begin{array}{c}\text { Baseline (A) } \\
\text { (minutes) }\end{array}$ & $\begin{array}{l}\text { Intervention (B) } \\
\text { (minutes) }\end{array}$ & $\begin{array}{c}\text { Baseline (A) } \\
\text { After intervention withdrawn } \\
\text { (minutes) }\end{array}$ \\
\hline \multirow{7}{*}{1} & 1 & 85 & 75 & 25 \\
\hline & 2 & 90 & 65 & 20 \\
\hline & 3 & 85 & 60 & 15 \\
\hline & 4 & 95 & 65 & 15 \\
\hline & 5 & 90 & 60 & 10 \\
\hline & 6 & 90 & 55 & 10 \\
\hline & 7 & 85 & 40 & 10 \\
\hline \multirow{7}{*}{2} & 8 & & 20 & \\
\hline & 9 & & 20 & \\
\hline & 10 & & 15 & \\
\hline & 11 & & 15 & \\
\hline & 12 & & 15 & \\
\hline & 13 & & 10 & \\
\hline & 14 & & 10 & \\
\hline
\end{tabular}

Table 2: Duration of Jeff's pacifier use time in minutes

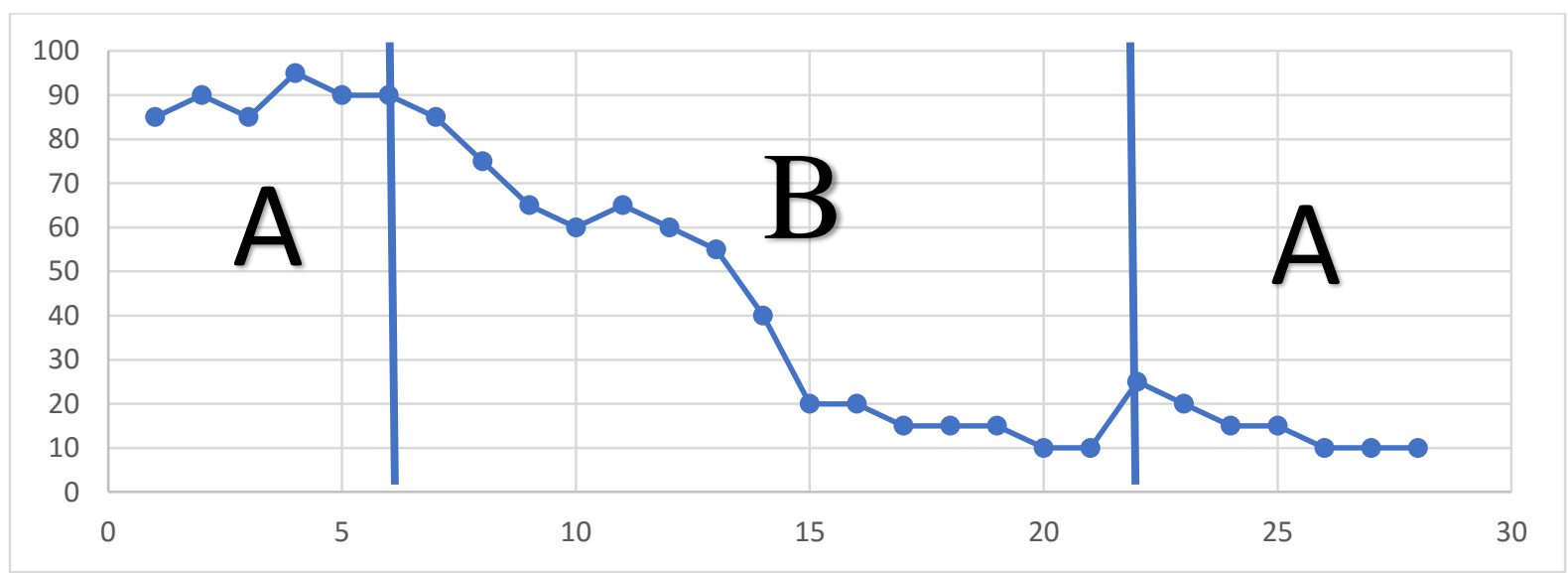

Graph 1 Frequency of pacifier use in the three phases of observation 
Vol. 8, No. 4, 2019, E-ISSN: 2226-6348 @ 2019 HRMARS

\begin{tabular}{lc}
\hline Phase & $\begin{array}{c}\text { Duration mean } \\
\text { (minutes) }\end{array}$ \\
\hline Baseline (A) & 88.6 \\
Intervention (B) & 37.5 \\
Baseline after removal of intervention (A) & 15.0 \\
\hline
\end{tabular}

Table 3: Mean of pacifier use in the three phases of observation

Our findings suggest that extrinsic reinforcement through a token economy program used in this study has been an effective strategy to manage behavioral concern. However, the study only involves one child, and the intervention was only provided for two weeks. The strategy may not be suitable for children who need stronger reinforcement options or if the actual reinforcements are incongruent with the norms of the child's social setting (Doll et al., 2013). There is also debate in the literature that extrinsic reinforcement may harm children's intrinsic motivation. However, a review of the literature on this debate suggests that "little detrimental effect is found with the use of external reinforcement programs" (Akin-Little, Eckert, Lovett, \& Little, 2004, p. 344). Extrinsic reinforcement is particularly important for the majority of children with disabilities because they often face difficulties to be intrinsically motivated (Matson \& Boisjoli, 2009). The use of extrinsic reinforcement is argued to be necessary to encourage development of internal motivators.

One strategy to ensure that positive behavior is sustained is to gradually fade off from tokens and substitute natural reinforcers (Jones \& Kazdin, 1975). Tangible reinforcements can be costly for long-term application. Current extrinsic reinforcement can also become satiated when it loses its reinforcement values (Singh, Lewis, Barto, \& Sorg, 2010). This study has demonstrated the importance of giving options for the child to choose because a single reinforcer may lose its appeal more easily when given too frequently. Continuous assessment of the behavioral support program is another strategy to ensure its effectiveness. This means that data collection is crucial for teachers or parents to monitor children's performance, despite this too being considered controversial because some progress may not be visible or easily measured.

\section{Conclusion}

In conclusion, this study reported the importance of reducing pacifier use for a five-year-old child with cerebral palsy. Observation found that the child had not used a pacifier during leisure time which allowed the child to improve his speech and social skills. It is also important to reduce the risk of oral abnormalities and problems. Improved opportunity to interact will subsequently improve other aspects of development including language, self-esteem and learning skills. Preparing children for these skills as early as possible could improve their school readiness. Inwardly-directed behaviors such as pacifier use are less recognized as problematic compared to outwardly- directed behaviors such as aggression. However, less focus on such behaviors also means that the consequences of the behavior may be overlooked. Behavioral problems should not be taken lightly regardless of whether they directly or indirectly affect the child and people 
Vol. 8, No. 4, 2019, E-ISSN: 2226-6348 @ 2019 HRMARS

around them. The findings from the current study suggest that it may be useful to support parents through the intervention process for addressing the needs of children with disabilities. A collaboration with all stakeholders will help children to grow to their full potential. Application of token economy has been shown to be effective and therefore worth further exploration. It is strongly suggested that investment in early and timely intervention will bring about long-term benefits to the affected children and their families.

\section{Acknowledgement}

The study was supported by the grant from the Faculty of Education, Universiti Kebangsaan Malaysia, GG2019-003.

\section{References}

Adair, S. M. (2003). Pacifier use in children: A review of recent literature. Pediatric Dentistry, 25(5), 449-458.

Akin-Little, K. A., Eckert, T. L., Lovett, B. J., \& Little, S. G. (2004). Extrinsic reinforcement in the classroom: Bribery or best practice. School Psychology Review, 33(3), 344-362.

Alias, A., \& Salleh, N. M. (2017). An analysis of problems faced by special education teacher in teaching multiple disabilities students. Journal of ICSAR, 1(1), 60-67.

Amran, H. A., Majid, R. A., \& Ali, M. M. (2019). Cabaran guru pendidikan khas pada abad ke-21 [Challenges for special education teachers in 21th century]. International Journal of Education, Psychology and Counseling, 4(26), 113-122.

Carneiro, N. C. R., Monteiro, L. R., Pordeus, I. A., \& Borges-Oliveira, A. C. (2017). Oral sucking habits among children with Down syndrome and cerebral palsy. Special Care in Dentistry, 37(4), 176-180. https://doi.org/10.1111/scd.12231

Doll, C., McLaughlin, T., \& Barretto, A. (2013). The token economy: A recent review and evaluation. International Journal of Basic and Applied Science, 2(1), 131-149. Retrieved from http://insikapub.com/Vol-02/No-01/12IJBAS(2)(1).pdf

Ferreira, H. R., Rosa, E. F., Antunes, J. L. F., Duarte, D. A., Imparato, J. C. P., Pannuti, C. M., \& Mendes, F. M. (2015). Prolonged pacifier use during infancy and smoking initiation in adolescence: Evidence from a historical cohort study. European Addiction Research, 21, 3338.

Hammond, D., \& Gast, D. L. (2010). Descriptive analysis of single subject research designs: 19832007. Education and Training in Autism and Developmental Disabilities, 45(2), 187-202.

Hanafin, S., \& Griffiths, P. (2002). Does pacifier use cause ear infections in young children? British Journal of Community Nursing, 7(4), 207-211.

Jenik, A. G., \& Vain, N. (2009). The pacifier debate. Early Human Development, (in press), 8-10. https://doi.org/10.1016/j.earlhumdev.2009.08.025

Jones, R. T., \& Kazdin, A. E. (1975). Programming response maintenance after withdrawing token reinforcement. Behavior Therapy, 6(2), 153-164. https://doi.org/10.1016/S00057894(75)80136-5

Kramer, M. S., Barr, R. G., Dagenais, S., Jones, P., Ciofani, L., \& Page, P. (2001). Pacifier use, early weaning and cry/fuss behavior. 286(3).

Marter, A., \& Agruss, J. C. (2007). Pacifiers: An update on use and misuse. Journal for Specialists 
Vol. 8, No. 4, 2019, E-ISSN: 2226-6348 @ 2019 HRMARS

in Pediatric Nursing, 12(4), 278-285.

Matson, J. L., \& Boisjoli, J. A. (2009). The token economy for children with intellectual disability and/or autism: A review. Research in Developmental Disabilities, 30(2), 240-248. https://doi.org/10.1016/j.ridd.2008.04.001

Miltenberger, R. G. (2015). Behavior modification: principles and procedures (6th ed.). Boston: Cengage Learning.

Mohamed, S., Alias, A., Ali, M. A., Majid, R. A., Tahar, M. M., Toran, H., \& Yasin, M. H. M. (2019). Tahap kesediaan guru prasekolah dalam pengajaran dan pembelajaran sosio emosi [Readiness of pre-school teachers in the teaching and learning of socio-emotional].

Mugweni, R., Chinyoka, K., \& Chinyoka, K. (2018). I Can't but I Can: Writing with the Left Hand in Primary School Classrooms. International Journal of Academic Research in Progressive Education and Development, 7(4), 376-386.

Odom, S. L., \& Strain, P. S. (2002). Evidence-based practice in early intervention/early childhood special education: Single-subject design research. Journal of Early Intervention, 25(2), 151160.

Ortega, A. O. L., Guimarães, A. S., Ciamponi, A. L., \& Marie, S. K. N. (2007). Frequency of parafunctional oral habits in patients with cerebral palsy. Journal of Oral Rehabilitation, 34(5), 323-328. https://doi.org/10.1111/j.1365-2842.2006.01703.x

Reitman, D., Murphy, M. A., Hupp, S. D. A., \& O'Callaghan, P. M. (2004). Behavior change and perceptions of change: Evaluating the effectiveness of a token economy. Child and Family Behavior Therapy, 26(2), 17-36. https://doi.org/10.1300/J019v26n02_02

Singh, S., Lewis, R. L., Barto, A. G., \& Sorg, J. (2010). Intrinsically motivated reinforcement learning: An evolutionary perspective. IEEE Transactions on Autonomous Mental Development, 2(2), 70-82. https://doi.org/10.1109/tamd.2010.2051031

Sljabat, F.N. (2018). Entrepreneurial Orientation, Barriers, Business Networks, and Internationalization Readiness: A Conceptual Framework for the SMEs, International Journal of Academic Research in Accounting, Finance and Management Sciences 8 (3): 95102

Sugai, G., Horner, R. H., Dunlap, G., Hieneman, M., Lewis, T. J., Nelson, C. M., ... Turnbull III, H. R. (2000). Applying positive behaviour support and functional behavioural assessment in schools. Journal of Positive Behavior Interventions, 2(3), 131-143.

Zirpoli, T. J. (2008). Positive behavioral supports: Reinforcement strategies. In T. J. Zirpoli (Ed.), Behavior Management: Applications for teachers (5th ed., pp. 302-337). New Jersey: Pearson Merill Prentice Hall. 